\title{
Treatment of Sebaceous Hyperplasia with Pulsed Dye Laser
}

\author{
LAILA M. MOHAMMED, M.D.; ARWA M. HASSAN, M.D. and EMAN E. EL-SHOBARY, M.Sc. \\ The Department of Dermatology and Venereology, Faculty of Medicine, Tanta University
}

\begin{abstract}
Background: Sebaceous hyperplasias are benign skin lesions mostly seen on the face. These lesions are a common cosmetic concern but are difficult to be treated, as the entire sebaceous gland needs to be destroyed. Multiple treatment modalities have been employed for the management of sebaceous hyperplasia but some therapies are associated with side effects and recurrence rates. The pulsed dye laser may be an effective and safe alternative treatment option.
\end{abstract}

Aim of Study: To evaluate the efficacy of pulsed dye laser in treating sebaceous hyperplasia.

Patients and Methods: Twenty patients with a total of 72 sebaceous hyperplasia lesions were treated by 1-3 sessions of pulsed dye laser, two weeks apart (with parameters of hand piece 7 , fluence $9-12 \mathrm{~J} / \mathrm{cm}$, pulse width $1.5 \mathrm{~ms}$, rate $1 \mathrm{HZ}$ and air cooling). The patients were assessed clinically to evaluate the efficacy and safety of PDL.

Results: $83.3 \%$ of lesions responded to treatment, with complete reduction in 46 lesions $(63.9 \%)$ and partial reduction in 14 lesions (19.4\%). Treatment was well tolerated with no side effects and high patient satisfaction.

Conclusion: Pulsed dye laser is effective and safe as a monotherapy for treating sebaceous hyperplasia.

Key Words: Sebaceous hyperplasia - Pulsed dye laser.

\section{Introduction}

SEBACEOUS hyperplasia is a benign cutaneous condition of sebaceous glands that causes cosmetic concerns in middle aged and elderly patients [1] It commonly appears as single or multiple soft yellowish papules of various sizes with a central umbilication, in highly sebaceous areas especially the face [2].

The pathogenesis surrounding sebaceous gland hyperplasia involves the changing hormonal environment that comes with increasing age [3]. Declining levels of androgens leads to a decrease in

Correspondence to: Dr. Laila M. Mohammed,

The Department of Dermatology and Venereology,

Faculty of Medicine, Tanta University sebocyte turnover that leads to an increase in sebocytes within the gland and thus hyperplasia. The effect is most pronounced over the face [4] Additional hormonal factors such as insulin, TSH and hydrocortisone have been found to increase sebocyte proliferation [5]. Extrinsic factors including UVB light [6] and immunosuppressant agents such as cyclosporine play a role in SGH [7].

Successful therapeutic modalities has been described including surgical excision, curettage, cryotherapy, chemical ablation and $\mathrm{CO} 2$ laser but all of which are aggressive and involve a high risk of scarring and pigmentary changes [8]

Pulsed Dye Laser (PDL) is considered the gold standard for many vascular indications, such as port-wine stains, haemangiomas, and telangiectasias. It has also gained FDA approval for the treatment of numerous nonvascular conditions, including, rhytides, benign cutaneous lesions such as acne, warts, psoriasis and scars and it is a good option in treating sebaceous hyperplasia $[9,10]$

PDL eliminates SGH quickly, easily, painlessly and only involves a transient purpuric effect. The effect of PDL could be explained by its selective action on the telangiectatic component of the lesion causing destruction of the vessels that nourish the sebaceous hyperplasia, leading to its reduction [11]

\section{Aim of the study:}

This study aimed to evaluate the efficacy of pulsed dye laser in treatment of sebaceous hyperplasia.

\section{Patients and Methods}

\section{Patients:}

The present study was carried out on 20 patients with sebaceous hyperplasia, diagnosed clinically on the basis of typical appearance of skin lesions. 
They were collected from the Outpatient Clinic of Dermatology and Venereology Department, Tanta University Hospitals over a period of 12 months from June 2016 - June 2017. The study was approved by the Research Ethics Committee and all participants signed an informed consent before participation in the study.

Patients with active infection, immunodeficiency conditions, wound-healing abnormalities, receiving hormonal treatment or systemic retinoids and those under chemical peeling and dermabrasion were excluded.

\section{Methods:}

Complete history taking, and full general and dermatological clinical examination were done for the patients.

Laser treatment for all patients with $595 \mathrm{~nm}$ PDL (DEKA, SynchroVasq, Serial number: QA3B2501. Italy). Local anesthesia (lidocaine cream) was applied 30 minutes before the technique. Pulsed dye laser was used with hand piece $7 \mathrm{~mm}$, fluence $9-12 \mathrm{~J} / \mathrm{cm}^{2}$, width $1.5 \mathrm{~ms}$, rate $1 \mathrm{HZ}$ and integrated air cooling system. All patients were subjected to one to three sessions of $595 \mathrm{~nm}$ pulsed dye laser, two weeks apart. Photographs were taken before and after treatment in order to assess the degree of clinical improvement.

Clinical efficacy of treatment was categorized into $(>75 \%)$ as excellent improvement, $(50-75 \%)$ as marked improvement, (25-50\%) as moderate improvement, $(<25)$ as mild improvement and no response when no improvement at the end of therapy.

\section{Statistical analysis of the data:}

Data were analysed using IBM SPSS software package Version 20.0. (Armonk, NY: IBM Corp) Qualitative data were described using number and percent. The Kolmogorov-Smirnov test was used to verify the normality of distribution Quantitative data were described using range (minimum and maximum), mean, standard deviation and median. Significance of the obtained results was judged at the $5 \%$ level.

\section{Results}

The results of this study revealed the following:

Clinical data:

The total number of patients was 20 patients including 10 females (50\%) and 10 males $(50 \%)$, their ages ranged from ( 40 to 73 ) years with a mean \pm SD of $(52.75 \pm 10.94)$ years and median about (52.50) years. Age of onset ranged from (30 to 67$)$ years with a mean \pm SD of $(48.65 \pm 10.80)$ years and median about (49.50) years. The duration of disease ranged from (6 months to 10 years) with a mean \pm SD of $(4.08 \pm 3.14)$ years and median about (3.50) years. Four patients had positive family history of sebaceous hyperplasia (20\%) and sixteen patients had negative family history of sebaceous hyperplasia (80\%). Eight patients had Fitzpatrick's skin type III (40\%) and twelve patients had Fitzpatrick's skin type IV (60\%).

Concerning the site of sebaceous hyperplasia, all lesions were in the face. There was 10 patients $(50 \%)$ had sebaceous hyperplasia in cheek, 6 patients $(30 \%)$ had sebaceous hyperplasia in chin, 2 patients $(10 \%)$ had sebaceous hyperplasia in eyelid, 14 patients $(70 \%)$ had sebaceous hyperplasia in forehead and 6 patients $(30 \%)$ had sebaceous hyperplasia in nose.

\section{Clinical results after pulsed dye laser therapy:}

- Regarding clinical evaluation of patient's improvement: Eight patients (40\%) showed excellent improvement, four patients $(20 \%)$ showed marked improvement, two patients $(10 \%)$ showed moderate improvement, two patients $(10 \%)$ showed mild improvement and four patients $(20 \%)$ showed no improvement.

- Regarding the rate of reduction of SH lesions: A total number of lesions of sebaceous hyperplasia was 72 ; complete reduction was noted in 46 lesions $(63.9 \%)$, partial reduction was noted in 14 lesions $(19.4 \%)$ and non reduction was noted in 12 lesions (16.7\%).

- Regarding patients' satisfaction: Fourteen patients $(70 \%)$ were satisfied and six patients $(30 \%)$ were not satisfied.

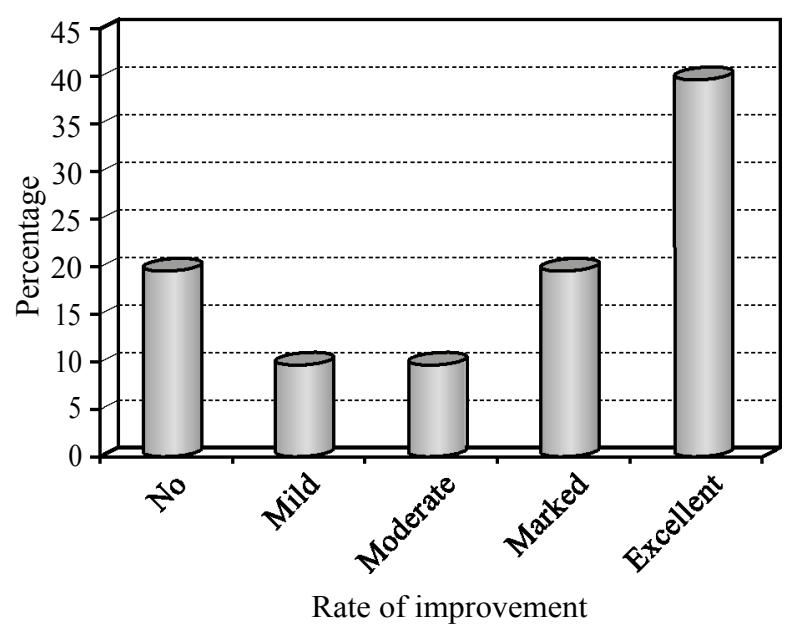

Fig. (1): Distribution of the studied cases of sebaceous hyperplasia according to rate of improvement $(n=20)$. 
Photo (1): A patient with sebaceous hyperplasia before treatment $(\mathrm{A}, \mathrm{C})$, and after pulsed dye laser therapy $(B, D)$ showing excellent improvement.

Photo (2): A patient with sebaceous hyperplasia before treatment $(\mathrm{A}, \mathrm{C})$, and after pulsed dye laser therapy $(B, D)$ showing excellent improvement.
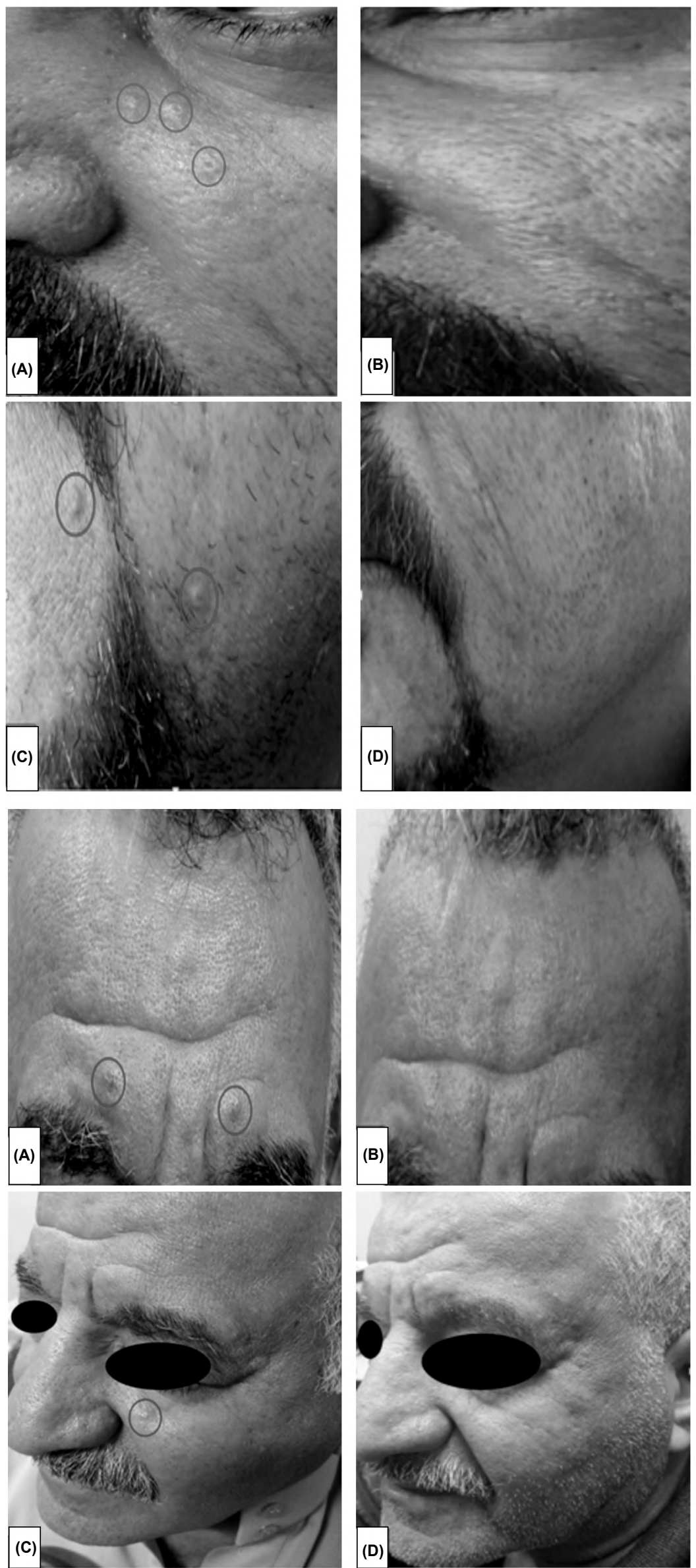


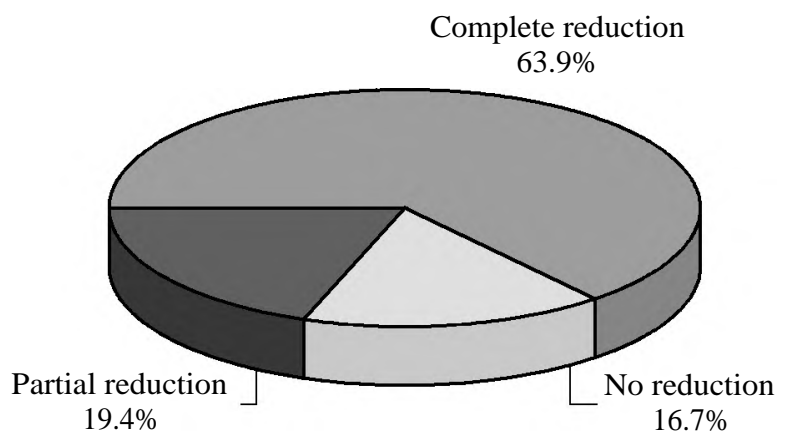

Fig. (2): Distribution of lesions of sebaceous hyperplasia according to reduction rate after treatment with pulsed dye laser.

\section{Discussion}

Treatment of $\mathrm{SH}$ is challenging because the entire sebaceous gland needs to be destroyed. Successful therapeutic modalities include cryotherapy, surgical excision, electrodessication, carbon dioxide laser and erbium-doped yttrium aluminium garnet (Er:YAG) laser [12]. However, these options bear the considerable risk of intra and postoperative bleeding, discoloration, and scar formation [9]. Oral isotretinoin has been used but has a high relapse rate with discontinuation. Photodynamic therapy has been reported to be effective, but the procedure is painful, expensive, and timeconsuming $[\mathbf{8 , 1 3}]$.

The principle of selective photothermolysis proposed by Anderson and Parrish in the early 1980 s, had led to a new generation of highly selective pulse lasers in dermatology. Pulsed Dye Laser (PDL) has been successfully used to treat many vascular lesions for the past 25 years such as port-wine stains, haemangiomas, and telangiectasias. It is regarded as the standard treatment for vascular malformations, such as port wine stain [14], and is also effective in treating numerous non vascular conditions including rhytides and benign cutaneous lesions such as verruca vulgaris, scars, striae, psoriasis, acne vulgaris and sebaceous hyperplasia by targeting feeding vessels of the lesions [15].

So, the aim of this study was to evaluate the efficacy of pulsed dye laser in the treatment of sebaceous hyperplasia.

In the current study, more than $80 \%$ of lesions responded to treatment, with complete reduction in $(63.9 \%)$ and partial reduction in (19.4\%). Also, $70 \%$ of patients were satisfied with treatment.

Current study agreed with the study of Wang et al., [16] which included eight patients with a total of $75 \mathrm{SH}$ lesions who were treated with pulsed dye laser in split face study. One side was treated with two sessions of 595-nm SPDL with 0.45 millisecond pulse duration, $5 \mathrm{~mm}$ spot size and 9$11 \mathrm{~J} / \mathrm{cm}^{2}$ fluence, and the other side was treated with two sessions of 595-nm LPDL with 20 millisecond pulse duration, $5 \mathrm{~mm}$ spot size and 13-21 $\mathrm{J} / \mathrm{cm}^{2}$ fluence. After the first session, all SH lesions responded to single SPDL treatment with complete reduction in five of 42 lesions $(11.9 \%)$ and partial reduction in 37 of 42 lesions (88.1\%). By contrast, none of the lesions completely disappeared after receiving single LPDL treatment, while partial reduction was noted in 21 of 33 lesions $(63.6 \%)$ and nonresponse in 12 of 33 lesions (3 6.4\%). All SH lesions responded to two sessions of SPDL or LPDL treatments with complete reduction in 20 of 42 lesions (47.6\%) treated by SPDL and in 11 of 33 lesions (33.3\%) treated by LPDL. The rest of the lesions all showed partial reduction.

Good results were stated by Schönermark et al., [9] who reported for the first time complete remission of sebaceous hyperplasia in two patients using 6.5 to $8 J / \mathrm{cm}^{2}$ (585nm, $0.45 \mathrm{~ms}, 5 \mathrm{~mm}$ ) after two to three treatments. Another study by Aghassi et al., [11] showed that the majority of sebaceous hyperplasia lesions responded to a single session of SPDL therapy ( 7 to $7.5 \mathrm{~J} / \mathrm{cm}^{2}, 585 \mathrm{~nm}, 0.45 \mathrm{~ms}$, $5 \mathrm{~mm}$ ), with a complete reduction in $28 \%$ and partial reduction in $93 \%$ of lesions. Also, Gonzales et al., [17] successfully treated a patient's sebaceous hyperplasias with $7 \mathrm{~J} / \mathrm{cm}^{2}$ (585nm, 5mm). Through confocal imaging, the authors were able to show selective photothermal damage confined to blood vessels.

In the current study regarding to side effects, all patients showed no side effects except mild pain and purpura. Efficacy for some conditions requires purpura as an endpoint, whereas nonpurpuric settings are effective for others [18]. This agreed with Schonermark et al., [9] and Gonzales et al., [17] who showed that treatment of sebaceous hyperplasia has no or minimal side effects.

Pulsed dye laser was found to be effective in treatment of sebaceous hyperplasia. The effect of PDL could be explained by its selective action on the telangiectatic component of the lesion, leading to destruction of the vessels that nourish the sebaceous hyperplasia [19].

In vivo $\mathrm{CM}$ was used to explain the involution of these lesions after laser therapy. It showed that a few minutes after application of the beam, the vessels surrounding the sebaceous duct were re- 
placed by amorphous and coagulated material. Selective photothermal damage was confined to the supporting microvasculature, followed by decreased epidermal hyperplasia within the ductal infundibulum, and a profound reduction in the size of the hypertrophic sebaceous gland, including undifferentiated sebocytes [17].

\section{Conclusion:}

Pulsed dye laser therapy was proved clinically to be safe and effective treatment modality for sebaceous hyperplasia. However, much more studies are still needed to confirm these findings.

\section{References}

1- ARSHAD A.M. and D'ANGELIS C.A.: Sebaceous Tumors of the Skin and Muir Torre Syndrome-A Mini-Review. N. A. J. Med. Sci., 7 (2): 87-92, 2014.

2- LIU H.H. and PERRY H.O.: Identifying a common and benign geriatric lesion. Geriatrics, 41 (7): 71-6, 1986.

3- ROSENFIELD R.L., DEPLEWSKI D. and GREENE M.E.: Peroxisome proliferator-activated receptors and skin development. Horm. Res., 54 (5-6): 269-74, 2000.

4- AKAMATSU H., ZOUBOULIS C.C. and ORFANOS C.E.: Control of human sebocyte proliferation in vitro by testosterone and 5-alpha-dihydrotestosterone is dependent on the localization of the sebaceous glands. J. Invest. Dermatol., 99 (4): 509-11, 1992.

5- ZOUBOULIS C.C., XIA L., AKAMATSU H., SELTMANN H., FRITSCH M., HORNEMANN S., et al.: The human sebocyte culture model provides new insights into development and management of seborrhoea and acne. Dermatology, 196 (1): 21-31, 1998.

6- LESNIK R.H., KLIGMAN L.H. and KLIGMAN A.M.: Agents that cause enlargement of sebaceous glands in hairless mice. II. Ultraviolet radiation. Arch. Dermatol. Res., 284 (2): 106-8, 1992.

7- SALIM A., REECE S.M., SMITH A.G., HARRISON D., RAMSAY H.M., HARDEN P.N., et al.: Sebaceous hyperplasia and skin cancer in patients undergoing renal transplant. J. Am. Acad. Dermatol., 55 (5): 878-81, 2006.

8- RICHEY D.F.: Aminolevulinic acid photodynamic therapy for sebaceous gland hyperplasia. Dermatol. Clin., 25 (1): 59-65, 2007.
9- SCHONERMARK M.P., SCHMIDT C. and RAULIN C. Treatment of sebaceous gland hyperplasia with the pulsed dye laser. Lasers Surg. Med., 21 (4): 313-6, 1997.

10- SCHONERMARK M.P. and RAULIN C.: Treatment of xanthelasma palpebrarum with the pulsed dye laser. Lasers Surg. Med., 19 (3): 336-9, 1996.

11- AGHASSI D., GONZÁLEZ E., ANDERSON R.R., RAJADHYAKSHA M. and GONZÁLEZ S.: Elucidating the pulsed dye laser treatment of sebaceous hyperplasia in vivo with real time confocal scanning laser microscopy. J. Am. Acad. Dermatol., 43 (1): 49-53, 2000.

12- BADER R.S. and SCARBOROUGH D.A.: Surgical pearl: Intralesional electrodesiccation of sebaceous hyperplasia. J. Am. Acad. Dermatol., 42 (1): 127-8, 2000.

13- ALSTER T.S. and TANZI E.L.: Photodynamic therapy with topical aminolevulinicacid and pulsed dye laser irradiation for sebaceous hyperplasia. J. Drugs Dermatol., 2 (5): 501-4, 2003.

14- YANG B., YANG O., GUZMAN J., NGUYEN P., CROUZET C., OSANN K.E., et al.: Intraoperative, realtime monitoring of blood flow dynamics associated with laser surgery of port wine stain birthmarks. Lasers Surg. Med., 47 (6): 469-75, 2015.

15- LIU A., MOY R.L., VICTOR ROSS E., HAMZAVI I. and OZOG D.M.: Pulsed dye laser and pulsed dye lasermediated photodynamic therapy in the treatment of dermatologic disorders. Dermatol. Surg., 38 (3): 351-66, 2012.

16- WANG S.P., CHANG Y.J., CHI C.C., WANG S.H. and TSAI T.H.: Using pulsed dye laser to treat sebaceous hyperplasia: Comparison of short and long pulse-duration pulsed dye laser. Dermatologica Sinica, 35 (3): 119-23, 2017.

17- GONZÁLEZ S., WHITE W.M., RAJADHYAKSHA M., ANDERSON R.R. and GONZÁLEZ E.: Confocal imaging of sebaceous gland hyperplasia in vivo to assess efficacy and mechanism of pulsed dye laser treatment. Lasers Surg. Med., 25 (1): 8-12, 1999.

18- ADAMIC M., TROILIUS A., ADATTO M., DROSNER M. and DAHMANE R.: Vascular lasers and IPLS: Guidelines for care from the European Society for Laser Dermatology (ESLD). J. Cosmet Laser Ther., 9 (2): 113-24, 2007.

19- TRUCHUELO M.T., ALLENDE I., ALMAZÁNFERNÁNDEZ F.M. and BOIXEDA P.: Pulsed dye laser treatment for multiple sebaceous hyperplasia secondary to ciclosporin. Actas Dermo-Sifiliográficas (English Edition), 102 (6): 470-1, 2011. 


\section{علاج تضخم الغدد الدهنية بليزر الصبغة النابضة}

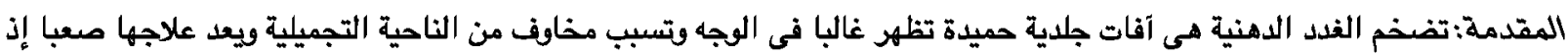

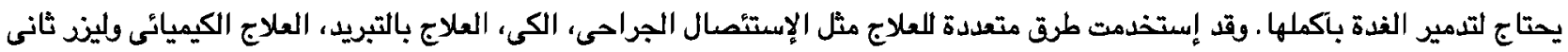

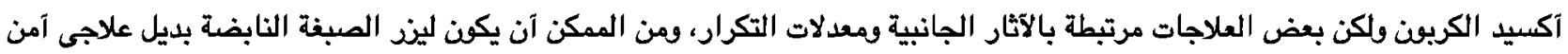

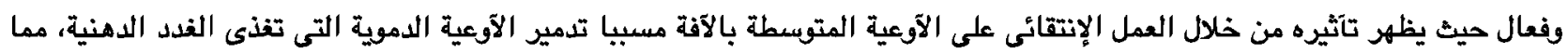
يؤدى إلى إختزالها .

$$
\text { الهدف من الدراسة: تقييم فاعلية ليز الصبغة النابضة فى علاج تضخم الغدل الدهنية. }
$$

المرضى وطرق البحث: إثتملت الدراسة على عشرين مريضا بإجمالى VY آفه من الغدد الدهنية المتضخمة تم جمعهم من العيادات

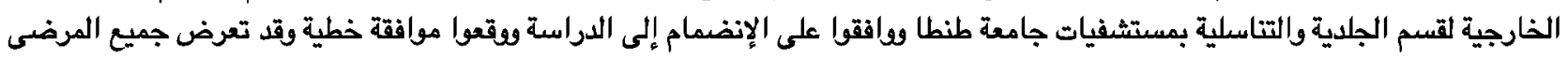

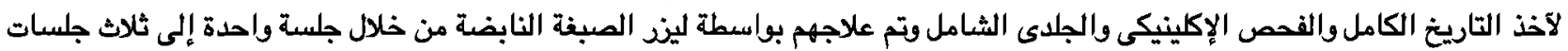

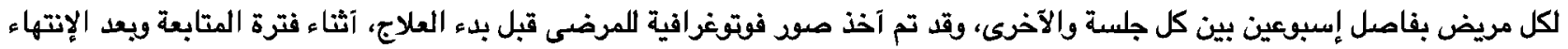

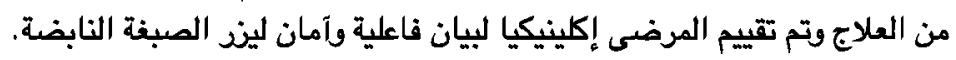

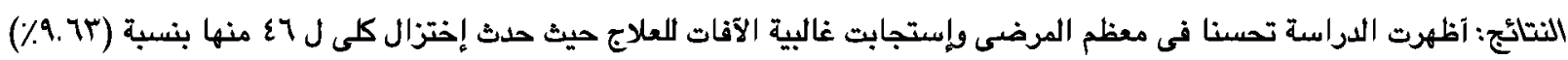

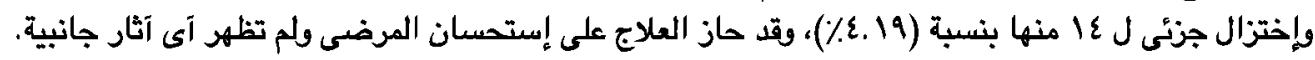
الإستستاج: نستنتج من هذه الدراسة آن جهاز ليز الصبغة النابضة فعال وآمن فى علاج تضخم الغدل الدهنية. 